\title{
IMAGINARIO MONÁRQUICO LIMEÑO ENTRE 1809 Y 1821: LOS HIPOTÉTICOS CANDIDATOS AL TRONO PERUANO DE LA CASA DE BORBÓN
}

\author{
Arnaldo Mera Ávalos \\ Pontificia Universidad Católica del Perú
}

\begin{abstract}
RESUMEN
Nos interesa analizar la posible evolución del pensamiento limeño en cuanto a la movilidad dinástica que se dio en el virreinato del Perú durante el gobierno del virrey marqués de la Concordia entre 1809 y 1812 . Hechos que no han sido tomados en cuenta pero pudieron causar honda impresión en los limeños y en su imaginario monárquico junto con la lectura de las Guías de forasteros que los llevó proponerle al general San Martín en 1820 para que este negociara con la máxima autoridad hispana en Lima el virrey; la posibilidad de que asumiera un miembro de la casa de Borbón una hipotética corona peruana.
\end{abstract}

\section{PALABRAS CLAVE}

Historia del Virreinato / Historia del Protectorado / Independencia. Monarquía / Genealogía

\begin{abstract}
Imaginary Monarquic Limeno between 1809 and 1821: The Hypothetical candidates for the Peruvian crown of the house of Borbon. We are interested in analizing the possible evolution of the limeno's way of thinking regarding the dynastic mobility that took place in the viceroyalty of Peru during the government of marquis viceroy of la Concordia between 1809 and 1812 . Facts that have not been taken in to account but could cause a deep impression in Limenos and in their monarquic imagination along with the reading of the guides for foreigners that in 1820 made then propose the general San Martin to renegotiate with the Spanish maximum authority in Lima the possibility crowned a member of Borbon dynasty in a hypothetical kingdom of Peru.
\end{abstract}

\section{KEY WORDS}

History of Viceroyalty / History of Protectorate / Independence. Monarchy / Genealogy 


\section{LA CRISIS DINÁSTICA DE 1808}

El 14 de octubre de 1808 el virrey Fernando de Abascal hacía jurar en Lima al nuevo soberano que como bien acota Sánchez Mantero: "El monarca encarnaba la soberanía de la nación y ese principio estaba en todo su vigor cuando Fernando VII sustituyó a su padre en el trono". Era una monarquía absoluta "que no había sufrido merma en cuanto a la soberanía del rey. En efecto, en el Antiguo Régimen, el rey constituía el poder jerárquico más elevado después de Dios, y era fuente de toda justicia, de toda legislación y quien manejaba las riendas del Gobierno"2. Bien nos hace recordar Landavazo que

Hace algunos años François Xavier Guerra observó que la monarquía española a pesar de su diversidad étnica, social y regional, se había revelado como una comunidad humana de una notable homogeneidad cultural y política en las reacciones que se produjeron tras la crisis de 1808. E hizo notar de igual forma, que lo más destacado de esas reacciones fue el lugar central que ocupó en el imaginario político la figura del rey. En la medida en que el monarca aparecía como indisolublemente ligado a la nación, y la ofensa a aquél era vista como una ofensa a esta, por lo que los discursos de la resistencia a los franceses adquirieron una tonalidad patriótica evidente ${ }^{3}$.

Ello lo comprobamos para el caso peruano, cuando la prensa limeña reprodujo ataques a la dinastía usurpadora. Así el 22 de enero de 1809 se publicó una "Genealogía de Bonaparte"4 y hace bien en señalar Armando Nieto Vélez que "las frases citadas de la chusca genealogía fueron realmente un arma de ataque, pues al recurrir a estas particularidades de la vida privada de la familia Bonaparte, se contribuía a desprestigiarla enormemente y mejor que con cualquier otro medio"s. En el imaginario monárquico de los limeños se defendía a su dinastía la Casa de Borbón de la dinastía intrusa y advenediza.

Sánchez Mantero Rafael. Fernando VII. Madrid: Arlanza Ediciones 2001 p. 219. Íd., loc. cit.

Landavazo, Marco Antonio. Nacionalismo y violencia en la Independencia de México. Toluca de Lerdo: Gobierno del Estado de México, 2012, p. 26 citando a François- Xavier Guerra, Modernidad e Independencias. Ensayo sobre las revoluciones hispánicas. México: Fondo de Cultura Económica, 1993, pp. 149-150.

4 Minerva Peruana $\mathrm{N}^{\circ}$ 7. Ed. Extraordinaria del 22 de enero de 1809.

5 Nieto Vélez, Armando, Contribución a la historia del fidelismo en el Perú, 1808-1810. Boletín del Instituto Riva-Agüero. No 4. 1958-1960, p. 79. 
Así mismo Nieto Vélez estudia las pretensiones de la hermana mayor del rey cautivo la infanta Carlota Joaquina ${ }^{6}$ que buscaba resguardar bajo su mando los dominios de América e inclusive sugería que su primo el infante Pedro Carlos sería enviado "para arreglar los asuntos de gobierno". Nieto Vélez citando a Rubio nos dice que este infante fue siempre enemigo declarado de los españoles, y sus condiciones no eran idóneas para el gobierno como lo lamentase inclusive su misma prima ${ }^{7}$. El punto álgido del carlotismo fue cuando el virrey Abascal recibió la visita de Federico Douling quien arribó al Callao en la fragata Higginson-senior ${ }^{8}$. Nieto Vélez le dará la razón a Riva-Agüero y Osma al decirnos que el carlotismo de los limeños y peruanos de aquel entonces "se reducía a desear que la Infanta salvaguardara por el momento la quietud de las colonias sin admitir por eso la unión con la corona portuguesa ni la alteración de la fidelidad a Fernando VII"9 y concluirá que

Fidelismo y carlotismo no son por fuerza doctrinas inconciliables, puesto que en el fondo de una y otra latía una misma intención. Ahora bien esta afirmación no nos puede llevar a desconocer lo que efectivamente hubo de apresurado, de inoportuno, de anómalo en la conducción de las gestiones de Carlota Joaquina Y esto: lo apresurado, lo inoportuno, lo anómalo que hirió de modo insanable la buena fe de muchos hizo que "Carlotismo" viniera a ser sinónimo de traición y de infidelidad ${ }^{10}$.

Sabemos que posterior al período investigado por Nieto Vélez mediante bando se inserta la real orden por la cual se excluyó de la sucesión al trono de España a la Infanta Carlota Joaquina publicado en el Verdadero Peruano $\mathrm{N}^{\mathrm{o}} 8$ del jueves 12 de noviembre de $1812^{11}$. Ello debió de ser un tema muy comentando y debió de perjudicar definitivamente a los que hubiesen sido sus partidarios

E inclusive un tema nunca abordado por nuestra historiografía y que tuvo que ser manejado cuidadosamente por el virrey Abascal fue cuando

\footnotetext{
Íd., Véase el Capitulo V, pp. 59-69.

Íd., p. 64 citando a Rubio, Julián María. p. 19 (no menciona el nombre del libro)

Íd., pp. 64-67.

Íd., p. 69 citando en nota a pie de página a Por la verdad, tradición y la Patria, I, p. 367.

10 Íd., loc. cit.,

11 Medina, José Toribio. La Imprenta en Lima 1811-1824. Santiago de Chile: Fondo Histórico y Bibliográfico José Toribio Medina, 1991, Tomo IV, p. 86.
} 
las Cortes reunidas en Cádiz cuestionaron la vigencia de los derechos a la corona española de uno de los miembros de la familia real española:

La labor de las cortes fue muy amplia y entre los muchos decretos reformadores que se aprobaron a lo largo de sus sesiones y que iban a afectar a Fernando VII hay que destacar aquellos que limitaban el poder de la monarquía"12 lo cierto es que también decidieron apartar de la línea de sucesión al trono al hijo menor de Carlos IV infante Francisco de Paula ${ }^{13}$ según Mateos "habían emitido un decreto de exclusión del infante a la corona de España basado en su supuesta bastardía ${ }^{14}$.

El mismo Mateos reitera en otra obra su afirmación de manera menos cruda cuando al hijo de este infante se le concedió el ducado de Cádiz en 1820 "El nuevo concesionario era el hijo del infante Francisco de Paula, cuya posición en la corte no estaba aún claramente definida pues años atrás había sido excluido de la sucesión a la Corona por las Cortes de Cádiz de 1812"15 Balansó es más preciso y nos dice que el decreto fue de fecha 18 de marzo de $1812^{16}$, pero no hemos encontrado su publicación en Lima aunque es un hecho innegable que el rumor debió de llegar a la corte virreinal pues se trataba del segundo en la línea de sucesión al trono que había sido apartado de la misma por decisión de los súbditos del soberano. Y el hecho de que su situación quedase incierta debió generar asimismo toda clase de conjeturas entre los monárquicos limeños y no sabemos que hayan tenido noticia del decreto del 17 de julio de 1820 que dejó invalidado el primero aduciendo que "Se ha examinado la proposición relativa a que por haber creado las circunstancias políticas que obligaron a excluir al infante, se revoque aquella disposición, que se fundó en la necesidad de precaver una nueva perfidia de Bonaparte"17. Ya que la noticia de dicho decreto debió ser opacada por la de su boda publicada en la Gaceta de Gobierno de inicios de setiembre de aquel año; como veremos más adelante. Lo interesante es que nunca fue retirado el

12 Sánchez Mantero Rafael. Op., cit, p. 86.

13 Sobre este infante y su relación con el Perú véase Mera Ávalos Arnaldo. "Efemérides dinásticas de los borbones en la corte de Lima 1708-1820". Boletín del Instituto Riva-Agüero, Lima, N³4, 2007-2008 pp. 114-115 y 120-121

14 Mateos Sainz de Medrano, Ricardo. Los desconocidos infantes de España, Casa de Bórbon. Barcelona: Thassalia, 1996, p. 113.

15 Mateos Sáinz de Medrano, Ricardo. Nobleza Obliga. Una historia intima de la aristocracia española: los Alba, los Romanones, los Urquijo... . Madrid: La esfera de los libros, 2006, p. 437.

16 Balansó, Juan. La corona vacilante. Barcelona: Plaza \& Janés, 1996, p. 120.

17 Íd., Loc., cit. 
nombre de este infante en la publicación del Almanaque peruano y guía de Forasteros..." después de 1812 y siguió en el mismo hasta 1821.

\section{EL REY DE ESPAÑA, ¿XXVI EMPERADOR DEL PERÚ?}

El exabrupto originado por la imposición de un rey extranjero en la metrópoli irrumpió la tranquilidad del virreinato y para prevenir confusiones a partir de la edición de 1809 del "Almanaque peruano y guía de Forasteros..." para evitar dudas sobre el legítimo soberano hispano y su familia se publicó antecediendo a todas las autoridades del virreinato la línea de sucesión de la Casa de Borbón al trono español y ello continuó hasta 1821 año del final de la dominación hispana en el Perú. Nos dice Schwab que los Almanaques peruanos pertenecieron al tipo de las efemérides dentro de una clasificación más específica. Y nos dijo, a su vez que las Guías de Forasteros tuvieron su antecedente en los calendarios de la corte, en general y en la Guía de forasteros de Madrid ${ }^{18}$; al respecto afirma Schwab "es muy probable que la Guía de forasteros de Lima haya nacido por órdenes emanadas del poder metropolitano y no sólo por imitación. Es curioso anotar que desde la fecha de la oficialización de la Guía de Madrid hasta la aparición de la primera Guía de forasteros de Lima habían transcurrido ocho años"19. Nos sigue ilustrando Schwab que cuando al Almanaque peruano se le agrega en 1779 la Guía de forasteros,

El carácter oficial queda fuera de duda [...] informando sobre todo el mecanismo administrativo del Gobierno virreinal [...] El carácter oficial se revela claramente en la real orden expedida en Aranjuez el 4 de junio de 1791 y dirigida al virrey del Perú, expresando que el Rey, desea se remita anualmente suficiente número de "Guía de forasteros" para S.M. y demás personas reales y algunas más para el departamento de Hacienda ${ }^{20}$.

Lo interesante de la Guía de Forasteros de 1809 es que consideramos por lo expuesto líneas arriba que debió de estar autorizada por la autoridad virreinal en aquel año después de la crisis de 1808, y por ello el Superior

18 Schwab, Federico.” Los Almanaques peruanos y guías de forasteros ¿1680?1874". Boletin Bibliográfico. Biblioteca Central. Universidad Nacional de San Marcos. Lima, Año XXI. Vol. XVIII. No 1-2, junio, 1948, p. 79.

19 Íd., p. 83.

20 Íd., loc., cit. véase Libro de Reales Ordenes desde el año de 1769 a 1801, pp. 205-206. Manuscritos existentes en el Archivo Histórico del Ministerio de Hacienda y Comercio de Lima, con la signatura 900. 
Gobierno debió de estar enterado e informado que se había denominado al rey de España como emperador del virreinato peruano. Asimismo el autor de la Guía, le colocó al denominado soberano imperial la numeración vigesimosexta correspondiente como sucesor legítimo de Manco Cápac y así figuró entre 1809 y 1820 en las ediciones anuales de aquel "Almanaque Peruano y Guía de Forasteros" y sólo es retirada dicha denominación para la edición de 1821 cuando la Expedición Libertadora del general San Martín ya se encontraba en territorio peruano desde inicios de setiembre del año anterior; y, creemos que fue aun más necesaria retirar dicho título imperial dado de manera gratuita al soberano a raíz de que se le planteó al virrey Pezuela la posibilidad de colocar a un infante de la familia real española en el trono de un reino peruano independiente.

Un antecedente de dicha denominación poco conocido y rescatado por Macera será la realizada a fines del siglo XVII por dos indomestizos nobles peruanos el primero Bernardo Inga "asumió una postura genealógica oficialista. Según él la varonía de Huayna Cápac feció con la muerte de don Melchor Carlos. Sólo subsistían las estirpes vinculadas a coyas y ñustas. Esta postura beneficiaba no solamente a los propios reyes españoles [...] sino que además permitía incrementar las aspiraciones de indios mestizos y criollos vinculados fuese a la descendencia femenina inca o a las panacas anteriores a Huayna Capac." ${ }^{21}$ Creemos que la extinción de la rama masculina primogénita era un tema de dominio público entre la elite limeña y que tuvo sus consecuencias para no buscar a un linaje oriundo del Perú; más bien resulta muy interesante la otra fuente señalada por Macera en la cual

para Juan Núñez de Vela sólo fueron once los incas gentiles que terminaron con Huayna Cápac y no menciona a la línea de Vilcabamba [...] De modo que el emperador Carlos es mencionado como Inga XII. Con lo cual según Núñez Vela la gran monarquía hispana fue convertida en una monarquía mestiza. En Línea sucesoria seguían Felipe el Prudente- Inga XIII, Felipe el Piadoso-Inga XIV, Felipe Grande-inga XV, Carlos II-Inga Católico XVI22.

Además Wuffarden nos dice que el presbítero mestizo arequipeño Juan Núñez Vela y Ribera impulso "la creación de un programa iconográfico basado en las ideas en las ideas que el propio Núñez Vela había esbozado ya en 1694. A propósito de las peticiones de los curacas, su representante

21 Macera, Pablo. El Inca colonial. Lima: Fondo Editorial UNMSM, 2004, p. 11.

22 Íd., loc., cit. 
los instaba a investir con el título de "inga" a los monarcas españoles del Perú, añadiendo sus nombres a la "Real Serie de los Incas Gentiles, Señores naturales del opulentisimo Reyno del Perú"23. Wuffarden situa alrededor de 1725 este exitoso programa iconográfico plasmándose en una estampa calcográfica, así como en varias versiones pictóricas, tres de ellas han llegado al presente ${ }^{24}$. A su vez nos dice Quiroz que "Este patrón se repetirá en versiones históricas posteriores de la nobleza indígena que da a entender que los monarcas españoles no conquistaron el país de los incas sino que lo sucedieron en el mando de común acuerdo" 25 .

El tercer antecedente que creemos fue ampliamente conocido por los limeños a partir de sus respectivas publicaciones serán los proporcionados por Pedro Peralta y Barnuevo quien es probable haya tomado del texto anteriormente citado, la idea del "Inca Católico" dado al de quién monarca español en $1723^{26}$. Que, según Quiroz, es una temprana "referencia a los incas, de una manera sesgada en un "compendio del origen y serie de los incas" ${ }^{27}$, que inserta en su relato o descripción de sus Júbilos de Lima..., el único ejemplar que se conoce se conserva en la Biblioteca de Palacio Real y nos permite acceder a la celebración más importante del reinado de Felipe V efectuada en Lima por el doble compromiso de dos hijos del soberano: de Luis Príncipe de Asturias y de la infanta María Ana Victoria con el rey de Francia Luis XV. Hemos hecho larga mención de ello en una investigación sobre las Efemérides dinásticas de los borbones en la corte de Lima 1708-1820 de estas fiestas reales de $1723^{28}$ en la cual los indios de Lima presentaron la historia de los reyes incas como parte de su historia, ${ }^{29}$,

23 Wuffarden, Luis Eduardo. La descendencia real y el "renacimiento inca" en el virreinato" En Los Incas Reyes del Perú. Lima Banco de Crédito del Perú. 2005, p. 232.

24 Íd., loc., cit.

25 Quiroz Chueca, Francisco. De la Patria a la Nación. Historiografía peruana desde Garcilaso hasta la era del guano. Lima: Fondo Editorial de la Asamblea Nacional de Rectores, 2012, p. 130,

26 Íd., loc., cit.

27 Íd., p. 111.

28 Mera Ávalos, Arnaldo.Op. cit., 2011, pp. 103-106.

29 En la primera máscara "en danza doce indios acompañaron la representación del Chimo Cápac y otros doce al Inca Huáscar, Huayna Cápac estuvo rodeado de doce incas mientras Túpac Yupanqui solo de ocho; Pachacútec de diez individuos ataviados con las prendas de las tierras que conquisto: "Huancas, Taramas, Huaylas, Caxamarcas y otros. Wiracocha, Yahuar Huaca e Inca Roca iban acompañados también de ocho incas; Cápac Yupanqui, Mayta Cápac, Lloque Yupanqui, Sinchi Roca y Manco Cápac se los describe sin compañía alguna, 
reconociendo así mismo el dominio hispánico como legitimo al vincular ambas monarquías ${ }^{30}$. Será en una segunda obra: Lima Fundada de 1732 donde la idea imperial aparecerá mejor plasmada. Según Falla citado por Quiroz realiza una "evidente superposición del Perú por Lima, ciudad sede del imperio austral a la que él atribuye las virtudes de la grandeza del país; en efecto la ciudad simboliza el poder; así como lo hicieron Atenas, Roma, Florencia o Toledo"31. Quedará en la mente de los limeños la idea de ser la capital de un imperio y asociarán de una u otra forma la sucesión de los soberanos hispanos a los incaicos, a lo largo del siglo XVIII a través de pinturas y creemos que a pesar de la crisis de poder no fue considerada sediciosa la denominación de XXVI Emperador del Perú dada por los impresores de la Guía de forasteros, José Gregorio Paredes y Francisco Romero (entre 1810 y 1813), creemos con el beneplácito de la autoridad virreinal.

Lo cierto es que en aquel momento histórico el Perú era parte del reino de las Indias para el Imperio francés, pues es la denominación conjunta que se le da al soberano en el tratado de Valencay de fecha 11 de diciembre de $1813 .^{32}$ Pero encontramos que, a pesar de habérsela dado tratamiento de reino por una potencia de primer orden como lo fue en su momento el imperio napoleónico; a los pocos meses de haber sido restaurado Fernando VII (se le expidió los pasaportes el 7 de marzo de 1814, saliendo de Val encay

aunque se dejo constancia de que el actor que representó a Manco Cápac era V. Sonco Cusi Huallpa, noble principal del Cuzco. Y repitieron la misma máscara por segunda vez en la duodécima fiesta, pero omitieron representar al inca Yupanqui y respecto del séquito de Pachacútec, estuvo rodeado de chunchos en esta oportunidad, además la pompa triunfal estuvo acompañada de dos carros alegóricos. En la undécima presentaron un desfile de sesenta hombres a caballos, corrida de toros, una compañía de cuadrillas de treinta y dos hombres divididos en número de ocho uniformados como españoles, franceses y turcos y la cuarta vestidos de incas y se llevaron a cabo finalmente unas Alcancías".s/f en Peralta Barnuevo y Rocha, Pedro de. Júbilos de Lima y Fiestas Reales que hizo esta muy noble y leal Ciudad, Capital, Emporio de la América Austral, en celebración de los augustos casamientos del serenísimo señor don Luis Fernando Príncipe de Asturias, N señor con la serenísima señora princesa de Orleans y del señor Rey Cristianísimo Luis Décimo Quinto con la serenísima señora María Ana Victoria, Infanta de España, Ordenadas y dirigidas por el Excmo. Sor. D. Fr. Diego Morcillo Rubio de Aruñón, Arzobispo de la Plata Virrey Gobernador y Capitán General de los Reinos del Peru, Tierra Firme y Chile. Lima, 1723 s/f

30 Quiroz Chueca, Francisco. Op. cit., p. 130

31 Íd., p. 113, Citando a Falla:1999: 144. Por omisión del autor no aparece la referencia bibliográfica al final del libro.

32 Sánchez Mantero, Rafael. Op. cit., p. 82. 
el 13 de marzo y el 16 de abril llegó a Valencia ${ }^{33}$ ) el 24 de marzo de 1815 creó la Real Orden Americana de Isabel la Católica, la cual tenía “por objeto premiar la lealtad acrisolada, y el mérito contraído a favor de la defensa y conservación de los dominios de las Indias". ${ }^{34} \mathrm{El} 10$ de enero de 1816, a través de la Gaceta de Gobierno de Lima, la población limeña se enteraba de la creación de la nueva orden y con ello los limeños se enfrentaron a una cruda realidad pues no eran ni capital de un imperio y menos parte de un reino cruzando el Atlántico, pues Fernando VII no mencionaba de manera taxativa la existencia del reino de las Indias. Decía que: "movido mi real animo del aprecio y gratitud que tan justamente me merecen los eminentes y señalados servicios con que no pocos de mis beneméritos vasallos han contribuido y contribuyen así a la concordia y tranquilidad de los pueblos de mis dominios de indias". ${ }^{35}$ Así quedaba derrumbado un imaginario monárquico limeño y fueron repentinamente expuestos a una realidad que les disgustaba si bien no eran denominados colonias, si lo fueron como parte de un dominio. La Guía de forasteros será una ilusión esta también pudo ser una de las razones para que entre 1816 y 1820 los patriotas monárquicos limeños pensasen en buscar a un príncipe de la familia real para que reinase sobre el Perú.

\section{EL PLAN MONÁRQUICO DEL GENERAL SAN MARTÍN}

Como bien ha señalado Basadre, fue un extranjero el que dio "la primera, la más efectiva batalla por la monarquía en el Perú. El impulso de San Martín implica el más alto momento de auge de ilusión monarquista". ${ }^{36}$ Pero sería injusto dejar de lado a los patriotas limeños monárquicos, tanto de la nobleza titulada como de la que no era titulada y de los sectores altos y medios de tendencia conservadora, que buscaban ocupar tal vez aquellos puestos administrativos que señalaba la Guía de forasteros. Un problema que Landavazo haciendo un excelente resumen de Brading nos dice que aquel afirmó que "los sentimientos de animadversión contra los españoles europeos" de los criollos tuvieron "sus orígenes en el hecho de que aquellos eran favorecidos con los mejores empleos civiles, eclesiásticos y militares, una política que se intensificó a partir de 1750 cuando la corona abolió la venta de oficios y limitó los nombramientos de americanos para los puestos de gobierno. Las llamadas

33 Íd., p. 83 y pp. 116-117

34 Costa y Turrel, Modesto.Tratado completo de la ciencia del blasón ó sea código heráldico-histórico, acompañado de una extensa noticia de todas las ordenes de caballería existentes y abolidas. Madrid: Liberia Española., 1858, pp. 372-373.

35 Gaceta de Gobierno de Lima No 4 Lima, miércoles 10 de enero de 1816, 
Reformas Borbónicas agravaron las tensiones entre criollos y peninsulares, que para entonces eran ya seculares"37 Aquel imaginario monárquico pudo ser desarrollado en su propio beneficio por este estamento social patriota que intentaba ser el dirigente del virreinato peruano y debió de sugerirle al General San Martín los candidatos que podría haber propuesto en su momento; inclusive con la posibilidad de brindarle una información precisa debido al manejo de las 12 Guías de Forasteros entre 1809 y 1820 como lo veremos en el siguiente acápite con los cinco posibles candidatos de edad adulta.

No abundaremos en detalles acerca de las negociaciones sanmartinianas basta citar al maestro Basadre quien nos dijo que "Apenas desembarcado San Martín, inició Pezuela las negociaciones que condujeron a la conferencia de Miraflores (Setiembre 1820) donde en forma reservada fue planteada por los delegados del primero la coronación de un príncipe de España en el Perú independizado". ${ }^{38}$ Para el maestro de la Puente Candamo estas negociaciones "en ningún caso pasa de ser algo confidencial y, por lo tanto no puede considerarse a Miraflores como inicio del planteamiento monárquico sanmartiniano"39.

$\mathrm{Al}$ año siguiente se reabrieron las negociaciones con el nuevo virrey José de La Serna e Hinojosa en la casa hacienda de Punchauca y el 18 de mayo de 1821 se produjo la histórica entrevista entre San Martin y el nuevo virrey. En ella, además de obtener" un armisticio, "San Martin propuso allí el establecimiento de una regencia con un delegado por ambas partes y la presidencia de La Serna y que el mismo en caso necesario, iría a solicitar la venida de un príncipe de la casa reinante de España"40. Además nos dice De la Puente Candamo la presencia del comisionado Abreu fue hostil para el virrey y citando a su diario se refiere en la última conversación tenida entre dicho comisionado y San Martín antes de ingresar a Lima: Que conocía muy bien la impotencia de la América para erigirse en república independiente, por carecer de virtudes y civilización y que en estos extremos había convenido con los de su ejército en coronar a un príncipe español medio único capaz de ahogar las opiniones de enemistad, reunirse

37 Landavazo, Marco Antonio Op. cit., p. 18 cita a Brading, David A. Los orígenes del nacionalismo mexicano. México: Era, 1980, pp. 15-42

38 Basadre, Jorge. Op. cit., loc. cit.,

39 Puente Candamo, José Agustín de la. San Martin y el Perú. Planteamiento doctrinario. Buenos Aires: Nueva Mayoría, 2000, p. 49.

40 Basadre, Jorge. Op. cit., loc. cit., 
de nuevo las familias y los intereses [..."'41. Es innegable que el manejo de la información de la actualizada Guía de Forasteros para 1821 debió de tenerse en cuenta, donde, como veremos a continuación ya figuraban la descendencia de los dos hermanos menores del soberano.

\section{LOS POSIBLES CANDIDATOS DE LA CASA DE BORBÓN AL TRONO PERUANO}

Los dos primeros candidatos a los que hubiese recurrido la propuesta sanmartiniana habrían sido los dos infantes varones hermanos menores del rey Fernando VII, de los cuales los limeños tuvieron pleno conocimiento de su existencia desde el nacimiento de cada uno de ellos; de Carlos María Isidro nacido en $1788^{42}$ de 32 años de $\operatorname{edad}^{43}$ y de Francisco de Paula nacido

41 Puente Candamo, José Agustín de la. Op. cit., p. 57. Cita a B.M.B.T. Tomo 1, pp. 293-294.

42 Cédula "para que en los reinos de las Indias se den a Dios las debidas gracias por el nacimiento del infante Carlos María Isidro" a las 3 y 45 de la mañana del 29 de Marzo de 1788. Dada en Aranjuez el 20 de Abril de 1788. B.N.P. Sección Volantes V/C 303. y A.H. M. Libro N 30 de Cédulas y Provisiones de esta Ciudad de los Reyes que comienza en el año de 1791 fls. 116 y $117 \mathrm{r}$.

43 Nacido el 29 de marzo de 1788 En Guía de Forasteros de Lima para el año 1809 y para el año 1810 s/a, s/f y s/Editor. Paredes, Gregorio. Almanaque Peruano y Guía de Forasteros para el año de 1811. Lima Imprenta del Colegio de San Fernando 1810. s/f. Romero, Francisco. Almanaque Peruano y Guía de Forasteros para el año de 1812 Lima, Imprenta de los niños Huérfanos por Pedro Oyague, 1811. s/f. Romero, Francisco. Almanaque Peruano y Guía de Forasteros para el año de 1813. Lima Imprenta de los niños Huérfanos por Martin Saldaña, 1812. s/f. Romero Francisco. Almanaque y Guía de Forasteros para el año de 1814, Lima, Imprenta de los niños Huérfanos, 1813. s/f. Paredes, José Gregorio. Almanaque Peruano y Guía de Forasteros para el año de 1815. Lima Imprenta de los niños Expósitos, 1814. s/f. Paredes, José Gregorio. Almanaque Peruano y Guía de Forasteros para el año bisiesto de 1816. Lima, Imprenta de Bernardino Ruiz, 1815 s/f. Paredes, José Gregorio. Almanaque Peruano y Guía de Forasteros para el año de 1817. Lima Imprenta de Bernardino Ruiz, 1816. s/f. Paredes, José Gregorio. Almanaque Peruano y Guia de Forasteros para el año de 1818. Lima, Imprenta de Bernardino Ruiz, 1817. s/f. A partir de esta edición aparece su esposa la infanta de Portugal María Francisca de Asís nacida en Lisboa el 22 de abril de 1800 Paredes, José Gregorio. Almanaque Peruano y Guía de Forasteros para el año 1819. Lima Imprenta de Bernardino Ruiz 1818. s/f. Paredes, José Gregorio. Almanaque Peruano y Guía de Forasteros para el año bisiesto de 1820. Lima, Real casa de niños Expósitos, 1819. s/f. Paredes, José Gregorio. Almanaque Peruano y Guía de Forasteros para el año de 1821. Lima, Real casa de niños Expósitos, 1820. s/f. En esta ultima recién figura su hijo Carlos Luis nacido el 31 de Enero de 1818. 
en $1794^{44}$. Sobre el primero no tenemos noticias de haberse celebrado efeméride alguna por su natalicio, pero este infante dio de qué hablar a los limeños el 26 de noviembre de 1808, cuando en la Minerva Peruana se publicó una noticia inexacta que deformaba la realidad que se vivía por aquel entonces; en palabras de Nieto Vélez: "La primera y una de las más estupendas, dice que el pueblo francés, irritado por la ambición de Bonaparte, se reunió con el apoyo del Senado de París y con gran número de tropas condujo a España a Fernando VII, restituyéndolo en el trono el 17 de junio y que, luego de proclamar rey de Francia al infante Don Carlos, dio muerte al Emperador" 45

Sobre el segundo infante no cabe la menor duda que los limeños debían de recordar que durante el mandato del virrey bailío frey don Francisco Gil de Taboada y Lemus y Villamarín, este ordenó el 10 de agosto de 1794 celebrar el cumpleaños de la reina con un ejercicio militar para el lunes 25 y dispuso para el domingo 31 "en obsequio del día de San Ramón” grandes maniobras de "ataque a un reducto" festejando el nacimiento de aquel infante Francisco de Paula ${ }^{46}$. Dichas maniobras se realizaron en los Amancaes de San Bartolomé entre el Rímac y unos cerros que forman un anfiteatro con los de San Bartolomé y el Agustino al medio de los cuales quedaba la chacra de la Calera a extramuros de los Barrios Altos, pasando por las Portada de las Maravillas, el cercado y salidas intermedias ${ }^{47}$. Según Durand, anduvieron en el campo o en el lugar apropiado personajes como el oidor marqués de la Plata, auditor de guerra y nobles oficiales como los marqueses de Salinas y Montemira. ${ }^{48}$ A su vez "hubo gran concurso popular de todas las clases y abundaron bellas damas. La enorme concurrencia esparcida en los cerros y en torno al campo resultaba un espectáculo de por si"49. Así el virrey perennizó por mucho tiempo en la memoria de los habitantes de la ciudad el nacimiento de este infante que será consignado en el tercer lugar de sucesión y que tenía 26 años de edad cuando se dieron las conversaciones de San Martín

44 Cédula "para que en los reinos de las Indias se den a Dios las debidas gracias por el nacimiento del infante Francisco de Paula Antonio María" a las 5 y 30 de la tarde del 10 de Marzo de 1794. Dado en Aranjuez el 28 de Abril de 1794., A.H.M. Libro N 30 de Cédulas y Provisiones de esta Ciudad de los Reyes que comienza en el año de 1791 fls. 190 y 191 r.

45 Nieto Vélez, Armando. Op. cit., p. 113. Minerva Peruana, $\mathrm{N}^{\circ} 61$ del 26 de noviembre de 1808 .

46 Gazeta de Lima de 1793 a Junio de 1794. Gil de Taboada y Lemus. Lima, 1983, p. 144.

47 Id., p. 143.

48 Íd., p.. 148.

49 Ibíd., p. 148. 
con los virreyes Pezuela y La Serna. ${ }^{50}$ Además, ambos figuraron en el $\mathrm{Al}$ manaque Peruano y Guía de Forasteros desde 1809 hasta su última edición para 1821. Era de conocimiento reciente para los limeños la descendencia del segundo en la línea al trono, pues toda la población se había enterado en su momento a través de la lectura de la Gaceta o de oídas de que había contraído matrimonio en una doble boda en 1816 junto con su hermano el rey ${ }^{51} \mathrm{El}$ virrey Pezuela mediante bando del 25 de abril de 1817 hizo de conocimiento de la población la real cédula del 22 de marzo de 1816 que anunciaba la doble boda real ${ }^{52}$. Nos consta que los limeños oficialmente recién se habían enterado a través de la publicación en el Almanaque y Guía de Forasteros de 1821 que aquel infante había sido padre de un infante de 3 años de nombre Carlos Luis nacido el 31 de enero de $1818^{53}$. Respecto del hermano menor

50 Mateos Sáinz de Medrano, Ricardo. Los desconocidos infantes de España. Casa de Borbón. Barcelona: Thassalia 1996 p. 109. Nació el 10 de marzo de 1794 en Guía de Forasteros de Lima para el año 1809 y para el año 1810 s/a, s/f y s/Editor. Paredes, Gregorio. Almanaque Peruano y Guía de Forasteros para el año de 1811. Lima Imprenta del Colegio de San Fernando 1810. s/f. Romero, Francisco. Almanaque Peruano y Guía de Forasteros para el año de 1812 Lima, Imprenta de los niños Huérfanos por Pedro Oyague, 1811. s/f. Romero, Francisco. Almanaque Peruano y Guía de Forasteros para el año de 1813. Lima Imprenta de los niños Huérfanos por Martin Saldaña, 1812. s/f. Romero Francisco. Almanaque y Guía de Forasteros para el año de 1814, Lima, Imprenta de los niños Huérfanos, 1813. s/f. Paredes, José Gregorio. Almanaque Peruano y Guía de Forasteros para el año de 1815. Lima Imprenta de los niños Expósitos, 1814. s/f. Paredes, José Gregorio. Almanaque Peruano y Guía de Forasteros para el año bisiesto de 1816. Lima, Imprenta de Bernardino Ruiz, 1815 s/f. Paredes, José Gregorio. Almanaque Peruano y Guía de Forasteros para el año de 1817. Lima, Imprenta de Bernardino Ruiz, 1816. s/f. Paredes, José Gregorio. Almanaque Peruano y Guía de Forasteros para el año de 1818. Lima, Imprenta de Bernardino Ruiz, 1817. s/f. Paredes, José Gregorio. Almanaque Peruano y Guía de Forasteros para el año 1819. Lima Imprenta de Bernardino Ruiz 1818. s/f. Paredes, José Gregorio. Almanaque Peruano y Guia de Forasteros para el año bisiesto de 1820. Lima, Real casa de niños Expósitos, 1819. s/f. Paredes, José Gregorio. Almanaque Peruano y Guía de Forasteros para el año de 1821. Lima, Real casa de niños Expósitos, 1820. s/f. En esta ultima figura su esposa la Infanta Luisa Carlota nacida 24 de octubre de 1804 y su hijo Francisco de Asís nacido el 6 de mayo de 1820.

51 B.N.P. Sección Volantes V/C 303. Gaceta del Gobierno de Lima N 38 del jueves 9 de mayo de 1816, p. 295.

52 Medina Toribio, La Imprenta en Lima, Op. cit., impreso $\mathrm{N}^{0} 3348$ y nos dirá Medina que era una "hoja apaisada impresa por un lado a dos columnas con la real cédula" Tomo IV, p. 231.

53 Paredes, José Gregorio. Almanaque Peruano y Guía de Forasteros para el año de 1821. Lima: Real casa de niños expósitos, 1820. s/f. 
sabemos que la noticia de su boda fue la última efeméride dinástica publicada en la Gaceta de gobierno de Lima el 2 de septiembre de 1820 y decía para que: "se haga notorio haberse celebrado el matrimonio del infante don Francisco de Paula con la princesa Luisa Carlota de las dos Sicilias ${ }^{54}$ hija del duque de Calabria príncipe heredero del reino de Nápoles y de la infanta María Isabel ${ }^{55 "}$ ". La población limeña sabía que esta última se trataba de la hija menor del rey Carlos IV y que el contrayente era aquel hermano menor del rey tan mentado cuando fue desheredado en 1812. El rey comunicó a la población el 19 de junio de 1820 que "Se celebró corte en Nápoles el 15 de abril de 1819 según le participé a mi Consejo de Indias por reales decretos de 4 de octubre de 1819 y 18 de mayo de 1820 para que me acompañen en el regocijo propio de la dulce satisfacción que me causa este enlace, de que espero se sigan consecuencias muy favorables a mi corona y vasallos" ${ }^{\prime 56}$. Este matrimonio tuvo un hijo primogénito incluido en la Guía de Forasteros de 1821; Francisco de Asís nacido el 6 de mayo de $1820^{57}$. Nos dice el erudito Mateos que aquel pequeño nació sin corresponderle el rango de infante y su tío el rey le concedió por real cédula del 9 de mayo de 1820, el ducado de Cádiz, pero aquel niño sólo vivió un año y el ducado volvió a revertir a la corona $^{58}$ datos que no fueron consignados en la Guía de Forasteros de 1821.

El tercer candidato que podría haber figurado en la propuesta sanmartiniana hubiese sido el príncipe Carlos Luis de Borbón de 22 años de edad, quien era descendiente en cuarta generación de Felipe $\mathrm{V}$ primer Borbón que reinase en España. Hemos escrito acerca de cómo los borbones llegaron a reinar en Parma; ${ }^{59}$ su abuelo Fernando fue hecho infante de

acta del Gobierno de Lima No 53 del sábado 2 de setiembre de 1820 pp. 444 y 445. Cédula "para que en los reinos de las Indias se den a Dios las debidas gracias por el nacimiento de la infanta María Isabel" a las 6 de la tarde del 6 de julio de 1789. Dada en Madrid el 28 de Julio de 1789. A.H.M. Libro N 30 de Cédulas y Provisiones de esta Ciudad de los Reyes que comienza en el año de 1791, fls. 129 y 130. Y B.N.P Sección Volantes V/C 306.

56 Gaceta del Gobierno de Lima No 53 del sábado 2 de Setiembre de 1820 pp. 444-445.

57 Paredes, José Gregorio. Almanaque Peruano y Guía de Forasteros para el año de 1821. Lima, Real casa de niños Expósitos, 1820. s/f.

58 Mateos Sainz de Medrano. Op. cit., 2006, cap. VII Los Títulos concedidos a familiares de los reyes p. 437.

59 Mera Ávalos Arnaldo. "Las Armas del Rey de España en sus dominios del Perú". Boletín del Instituto Riva-Agüero N ${ }^{\mathrm{a}}$ 30, Lima, 2005, pp.299-300 y Kamen, Henry. Felipe V: El rey que reinó dos veces. Madrid: Temas de hoy, 2000 , pp. 254 y 258 
España por su primo Carlos III en $1765^{60}$ y su padre Luis fue reconocido en la dignidad de infante en $1795,{ }^{61}$ su madre fue la infanta María Luisa de España, ambos fueron reyes de Etruria, corona que Napoleón les concedió el 28 de julio de 1801 a cambio de la cesión de la Louisiana que realizó su suegro Carlos IV; la cual volvió a ser francesa ${ }^{62}$. Por lo tanto era sobrino del depuesto soberano español y además ostentaba el título de infante de España desde su nacimiento en $1799^{63}$. Se tenía absoluto conocimiento en Lima de esta rama dinástica desde dos décadas atrás ya que la boda de sus padres fue celebrada con una misa solemne en la catedral de Lima el 7 de agosto de 1796 y con tres noches de iluminación a partir del viernes 5 de agosto a las 7 de la noche ${ }^{64}$. Así mismo desde la aparición en el Almanaque Peruano y Guía de Forasteros de los días de los nacimientos de Rey y su real familia desde 1809 hasta 1815 aparecerá como "Carlos Luis, infante de España Rey de Etruria, sobrino del rey nació el 02 de dic de 1799"65. Desde el Almanaque Peruano y Guía de Forasteros de 1816 ya no figura como rey de Etruria y solo como Infante de España, hasta la última edición de $1821^{66}$.

60 "Dictamen Histórico de don Melchor Ferrer sobre la nacionalidad española de la casa de Parma". En María Teresa de Borbón Parma, Josep Carles Clemente „Joaquín Cubero Sánchez. Don Javier Una vida al servicio de la libertad. Barcelona: Plaza \& Janés, 1997, p. 393.

61 Íd., pp. 394-395.

62 Mateos Sáinz de Medrano, Ricardo. Op. cit., 1996, p. 89-99 y Balansó 1997 44-46

63 Mateos Sáinz de Medrano, Ricardo. Op. cit., 1996, p. 91

64 Mera Ávalos Arnaldo, Op. cit, 2011, p. 116

65 Guía de Forasteros de Lima para el año 1809 y para el año 1810. ambas s/a, s/f y s/Editor. Paredes, Gregorio. Almanaque Peruano y Guía de Forasteros para el año de 1811. Lima Imprenta del Colegio de San Fernando 1810. s/f. Romero, Francisco. Almanaque Peruano y Guía de Forasteros para el año de 1812. Lima, Imprenta de los niños Huérfanos por Pedro Oyague, 1811. s/f. Romero, Francisco. Almanaque Peruano y Guía de Forasteros para el año de 1813. Lima, Imprenta de los niños Huérfanos por Martin Saldaña, 1812. s/f. Romero Francisco. Almanaque y Guía de Forasteros para el año de 1814, Lima, Imprenta de los niños Huérfanos, 1813. s/f. Paredes, José Gregorio. Almanaque Peruano y Guía de Forasteros para el año de 1815. Lima Imprenta de los niños Expósitos, 1814. s/f.

66 Paredes, José Gregorio. Almanaque Peruano y Guía de Forasteros para el año bisiesto de 1816. Lima, Imprenta de Bernardino Ruiz, 1815 s/f. Paredes, José Gregorio. Almanaque Peruano y Guía de Forasteros para el año de 1817. Lima Imprenta de Bernardino Ruiz, 1816. s/f. Paredes, José Gregorio. Almanaque Peruano y Guía de Forasteros para el año de 1818. Lima, Imprenta de Bernardino Ruiz, 1817. s/f. Paredes, José Gregorio. Almanaque Peruano y Guía de Forasteros para el año 1819. Lima Imprenta de Bernardino Ruiz 1818. s/f. Paredes, José Gregorio. Almanaque Peruano y Guía de Forasteros para el año bisiesto de 1820. Lima, Real casa 
Sabemos de la existencia de un cuarto candidato que era bisnieto de Carlos III, hijo del infante Pedro Carlos y de la infanta portuguesa María Teresa, se trataba del infante Sebastián Gabriel de 20 años de edad nacido en Rio de Janeiro en 1811 infante de Portugal y de España ${ }^{67}$. No nos queda duda de que este infante fue considerado más un infante portugués pues nunca apareció en el Almanaque Peruano y Guía de Forasteros para los años de 1816 hasta 1821, a pesar que su padre quien falleció el 4 de julio de 1812 si figuró en dicho Almanaque entre los años de 1809 hasta 1815 como "Pedro Carlos Antonio Infante de España, primo del Rey, nació en 18 de junio de $1789 " 68$.

De la dinastía de Borbón que reinaba en Nápoles y Sicilia descendientes de un hijo de Carlos III de España, el rey Fernando IV, hermano menor de Carlos IV se tuvo pleno conocimiento de su existencia pues figuró en el Almanaque Peruano y Guía de Forasteros desde 1809 hasta 1821 como "Infante de España, tío del Rey, nació en 12 de enero de 1751"69. Quien será el primer soberano del recientemente denominado Reino de las Dos Sicilias después del Congreso de Viena; también los peruanos hubiesen tenido como

de niños Expósitos, 1819. s/f. Paredes, José Gregorio. Almanaque Peruano y Guía de Forasteros para el año de 1821. Lima, Real casa de niños Expósitos, 1820. s/f. 67 Mateos Sainz de Medrano, Ricardo. Op. cit., 1996, p. 131.

68 Guía de Forasteros de Lima para el año 1809 y para el año 1810. s/a, s/f y s/ Editor. Paredes, Gregorio. Almanaque Peruano y Guía de Forasteros para el año de 1811. Lima Imprenta del Colegio de San Fernando 1810. s/f. Romero, Francisco. Almanaque Peruano y Guía de Forasteros para el año de 1812 Lima, Imprenta de los niños Huérfanos por Pedro Oyague, 1811. s/f. Romero, Francisco. Almanaque Peruano y Guía de Forasteros para el año de 1813. Lima Imprenta de los niños Huérfanos por Martin Saldaña, 1812. s/f. Romero Francisco. Almanaque y Guía de Forasteros para el año de 1814, Lima, Imprenta de los niños Huérfanos, 1813. s/f. Paredes, José Gregorio. Almanaque Peruano y Guía de Forasteros para el año de 1815. Lima Imprenta de los niños Expósitos, 1814. s/f. Paredes, José Gregorio. Almanaque Peruano y Guía de Forasteros para el año bisiesto de 1816. Lima, Imprenta de Bernardino Ruiz, 1815 s/f. Paredes, José Gregorio. Almanaque Peruano y Guía de Forasteros para el año de 1817. Lima Imprenta de Bernardino Ruiz, 1816. s/f. Paredes, José Gregorio. Almanaque Peruano y Guía de Forasteros para el año de 1818. Lima, Imprenta de Bernardino Ruiz, 1817. s/f. Paredes, José Gregorio. Almanaque Peruano y Guía de Forasteros para el año 1819. Lima Imprenta de Bernardino Ruiz 1818. s/f. Paredes, José Gregorio. Almanaque Peruano y Guía de Forasteros para el año bisiesto de 1820. Lima, Real casa de niños Expósitos, 1819. s/f. Paredes, José Gregorio. Almanaque Peruano y Guía de Forasteros para el año de 1821. Lima: Real casa de niños expósitos, 1820. s/f.

69 Íd., loc. cit. 
quinto candidato al hijo de aquel rey Fernando, el príncipe Leopoldo ${ }^{70}$ de 30 años casado y con descendencia, y en su defecto a los hijos del príncipe Francisco heredero al trono, Carlos de 10 años y Leopoldo de 8 años, aunque estos niños que hubiesen sido el sexto y setimo candidato al trono hubiesen necesitado de una regencia y hubiese sido poco probable que se separan de sus padres a tan tierna edad; debemos de resaltar que la princesa heredera madre de aquellos dos príncipes, era hermana de Fernando VII, la infanta María Isabel $^{71}$ no hemos considerado en esta relación al príncipe Fernando primogénito de Francisco de 11 años y heredero presuntivo de la corona de su abuelo. Creemos que de haber continuado con éxito la negociación sanmartiniana no hubiese tenido trascendencia la circunstancia que fueran príncipes absolutistas y estuvieran luchando contra la revolución liberal que implantó en su reino la misma constitución que rigió en España y el Perú en 1812 , el 9 de julio de $1820^{72}$ ya que debían de cumplir con los requerimientos del jefe de su dinastía que era el rey de España Fernando VII.

\section{EPÍLOGO}

Finalmente, el tema fue abordado por el gobierno del Perú independiente en plena guerra de la Independencia, durante la dictadura de Simón Bolívar y desde Trujillo (ya que Lima se encontraba ocupada por el ejército realista) en un artículo del editor de la Gaceta de Gobierno de Lima del 12 de junio de 1824 titulado "la hipocresía sin máscara" (sic) en el se difundió el plan monárquico de los realistas para traer a un príncipe de la Casa de Borbón: "Este plan estaba reducido a proclamar la Independencia del Perú estableciendo un Imperio que abrazase el inmenso territorio que se comprende desde Humahuaca hasta Guayaquil coronando un príncipe de la casa de Borbón". ${ }^{3}$ Y porque no decirlo, esta pudo ser una idea de un imaginario monárquico más de los patriotas que no eran republicanos, por crear un Gran Perú que uniese el Alto y Bajo Perú además del recién recuperado puerto de Guayaquil (estuvo 17 años bajo el gobierno del virrey del Perú de 1803-1820) y que chocaba frontalmente con la idea de la Gran Colombia republicana y bolivariana.

70 Acton, Harold. I Borboni Di Napoli (1734-1825). Florencia: Gruppo Guinti, 1997, Tomo I, p. 242.

71 Íd., Tomo I, p 504

72 Íd., Tomo I, pp. 756-768

73 Gaceta de Gobierno de Lima, No 25, Lima, sábado 12 de junio de 1824, p. 4. 
Imagen $\mathrm{N}^{\circ} 01$

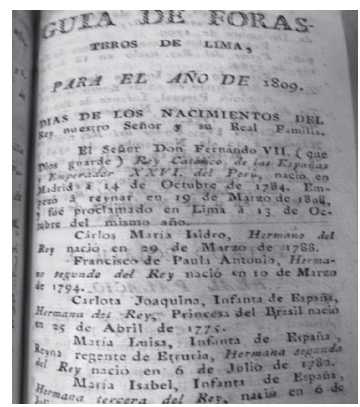

Se aprecia por primera vez que Fernando VII es el XXVI Emperador del Perú Almanaque Peruano y Guía de Forasteros para el año 1809 s/f.

Imagen $\mathrm{N}^{\circ} 02$

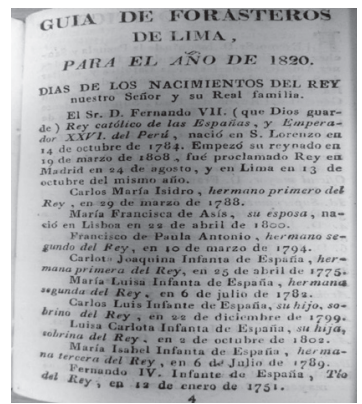

Última vez que figuró Fernando VII como XXVI Emperador del Perú. Almanaque Peruano y Guía de Forasteros para el año 1820 s/f.

\section{REFERENCIAS BIBLIOGRÁFICAS}

ACTON, Harold.

1997 I Borboni Di Napoli (1734-1825). Florencia: Gruppo Guinti, tomo I, p. 242.

BALANSÓ, Juan

1996 La corona Vacilante. Barcelona: Plaza \& Janés, p. 120. 
COSTA Y TURREL, Modesto

1858 Tratado completo de la ciencia del blasón ó sea código heráldico-histórico, acompañado de una extensa noticia de todas las ordenes de caballería existentes y abolidas. Madrid: Liberia Española, pp. 372-373.

GACETA DE GOBIERNO DE LIMA

1816 Lima, $\mathrm{N}^{\circ} 4$, miércoles 10 de enero.

1820 Lima, No 53, sábado 2 de setiembre, pp. 444 y 445.

LANDAVAZO, Marco Antonio

2012 Nacionalismo y violencia en la Independencia de México. Toluca de Lerdo: Gobierno del Estado de México, p. 26

\section{LIBRO DE REALES ÓRDENES}

1769-1801 Libro de Reales Órdenes, pp. 205-206. Manuscritos existentes en el Archivo Histórico del Ministerio de Hacienda y Comercio de Lima.

MACERA, Pablo

2004 El Inca colonial. Lima: Fondo Editorial UNMSM, p. 11.

MATEOS SÁINZ DE MEDRANO, Ricardo

1996 Los desconocidos infantes de España: Casa de Borbón. Barcelona: Thassalia, S.A., p. 113.

2006 Nobleza obliga. Una historia íntima de la aristocracia española: los Alba, los Romanones, los Urquijo. Madrid: La esfera de los libros, p. 437

MEDINA, José Toribio

1991 La Imprenta en Lima 1811-1824. Santiago de Chile: Fondo Histórico y Bibliográfico José Toribio Medina, tomo IV, p. 86

MERA ÁVALOS, Arnaldo

2007-2008 Efemérides dinásticas de los borbones en la corte de Lima 1708-1820. Boletín del Instituto Riva-Agüero. Lima, Na 34, 20072008, pp. 114-115 y 120-121

MINERVA PERUANA

$1809 \mathrm{~N}^{\circ}$ 7, Ed. Extraordinaria del 22 de enero. 
NIETO VÉLEZ, S.J., Armando

1958-1960 Contribución a la historia del fidelismo en el Perú 1808-1810.

Boletín del Instituto Riva-Agüero. Lima, número 4, p. 79

PAREDES, José Gregorio

1810 Almanaque Peruano y Guía de Forasteros para el año de 1811. Lima: Imprenta del Colegio de San Fernando

SÁNCHEZ MANTERO, Rafael

2001 Fernando VII. Madrid: Arlanza Ediciones, p. 219.

SCHWAB, Federico

1948 Los Almanaques peruanos y guías de forasteros ¿1680?-1874. Boletín Bibliográfico, Biblioteca Central. Universidad Nacional de San Marcos. Lima. Año XXI, Vol. XVIII, número 1-2, junio, p. 79

WUFFARDEN, Luis Eduardo.

2005 La descendencia real y "el renacimiento inca" en el virreinato. En Los incas, reyes del Perú. Lima, Banco de Crédito del Perú. p. 232. 